Research Paper:

\title{
Investigation of the Gap Between Patients' Perceptions and Expectations of Hospital Service Quality
}

\author{
${\text { Haniyeh } \text { Nazem }^{1} \mathbb{D} \text {, Hadi Raeis Abdollahi }}^{2} \mathbb{D}$, Abasat Mirzaei ${ }^{3,4^{*}}$ (D)
}

1. School of Nursing and Midwifery, Shahid Beheshti University of Medical Sciences, Tehran, Iran.

2. Department of Health Services Management, North Tehran Branch, Islamic Azad University, Tehran. Iran.

3. Department of Health Care Managment, Tehran Medical Sciences, Islamic Azad University, Tehran, Iran.

4. Health Economic Policy Research Center, Tehran Medical Sciences, Islamic Azad University, Tehran, Iran.

\begin{tabular}{|c|c|}
\hline $\begin{array}{l}\text { Use your device to scan } \\
\text { and read the article online }\end{array}$ & CFtation: Nazem $H$ Raeis Abdollahi_H Mirzaei_A 2020 In \\
\hline 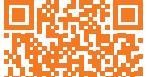 & $\begin{array}{l}\text { Expectations of Hospital Service Quality. Journal of Client-Centered Nursing Care, 6(2), pp. 117-124. https://doi.org/10.32598/ } \\
\text { JCCNC.6.2.286.1 }\end{array}$ \\
\hline 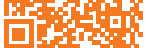 & dol'https://doi.org/10.32598/JCCNC.6.2.286.1 \\
\hline
\end{tabular}

\section{(c) (1) (8)}

Article info:

Received: 25 Dec 2020

Accepted: 23 Mar 2020

Published: 01 May 2020

Keywords:

Quality of service,

Perceptions, Expectations

\section{A B S T R A C T}

Background: Health care services are costly and complex and provide facilities that significantly affect the economy and quality of life of individuals. In this study, we determined the gap between patients' expectations and perceptions of hospital service quality to provide reference data for creating strategies to improve health care quality.

Methods: In this descriptive cross-sectional study, five private hospitals in Tehran were selected. Using a simple random sampling method, 110 patients were recruited and voluntarily responded to the standard service quality (SERVQUAL) model questionnaire. Data were analyzed by the K-S test, t-test, and paired t-test using SPSS V. 23.

Results: The results showed that among the quality of health care components, the highest mean was related to the responsiveness $(\mathrm{M}=3.89)$ and the least was related to the tangible dimension $(\mathrm{M}=3.11)$. The lowest average quality gap (perceived service and expected service) was seen in the responsiveness dimension (2.96 and 3.28) and followed by reliability (2.66 and 3.90), tangible (2.53 and 3.91), empathy (1.36, 3.19), and assurance dimensions (2.39 and 4.75).

Conclusion: The findings revealed a significant difference between the patients' perceived and expected services, which indicates that the quality of services as perceived by patients was lower than their expectations. According to the findings, the assurance dimension had the greatest gap. To reduce or eliminate the existing gap, it is suggested that hospitals consider strategic and operational planning to improve hospitalization experience, quality of medical services, and hospital resources.

\section{* Corresponding Author:}

Abasat Mirzaei, PhD.

Address: Department of Health Care Managment, Tehran Medical Sciences, Islamic Azad University, Tehran, Iran.

Tel: +98 (912) 7789006

E-mail: amacademic@yahoo.com 


\section{Highlights}

- The quality of services as perceived by patients was lower than their expectations.

- The assurance dimension had the greatest gap.

- The responsiveness dimension had the lowest gap.

\section{Plain Language Summary}

In this study, we examined the gap between perceptions and expectations of hospital service quality from the perspective of the patients referring to five private hospitals in Tehran. The lowest gap was observed in the responsiveness dimension, meaning that the patients had largely received the medical services they had expected. In other words, the patients believed that doctors and hospital staff are available at the time of their problems and are interested in a prompt resolution. Conversely, the greatest gap was observed in the assurance dimension. It means that the patients believed doctors and hospital staff do not have enough knowledge to help them and treat them with respect. In other words, the staff failed to create a sense of security and confidence in patients. It seems that holding briefings for staff on how to communicate with patients and keeping their dignity and conducting workshops and new diagnostic and therapeutic courses to provide services with the expected quality of patients will be effective in reducing the quality gap.

\section{Introduction}

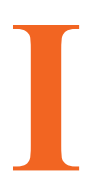

$\mathrm{n}$ the current century, the new developments have led to the expansion of the service sector and services are no longer a small part of the economy and are considered as a core of value creation.

Nowadays, the service sector provides the largest portion of the economy (Rezaei et al. 2016). The quality of service is also reflected in the correct understanding of the recipient's need and demand. In other words, the strategy is the key to the success and survival of any business enterprise and the provision of quality services to customers (Nadi et al. 2016) because the improvement of people's living standards has led them to look for the best quality products (Wong \& Sohal 2003).

Customer satisfaction, feelings, or attitudes towards a particular production or service are obtained after its use. Satisfaction and quality of services are often discussed as a subordinate of customer perceptions and expectations, and customer pleasure is determined by identifying their perceptions of quality, expectations, and priorities (Ajam et al. 2014; Mousavi et al. 2019). The problem faced by most organizations regarding the quality of service is the lack of focus on identifying and meeting the demands and wishes of customers (Asefzadeh et al. 2016).

Among various services, health care services as a global phenomenon, are costly and complex, because they provide services that significantly affect the economy and quality of life of individuals. Quality as one of the most important criteria for the development of the health services system has become one of the key concepts in macroeconomic policymaking. Hence, the quality of provision of health services has been considered as an important stage in the history of health system developments (Torabipour et al. 2016).

Regarding the importance of the type of services and its role in the improvement of human life quality, its quality assurance for the healthcare system and the people involved is crucial (Tabibi et al. 2012). Similar to the customers of the economic sector, the patients have also recently paid more attention to the quality of medical services (Wong \& Sohal 2003).

Since the main mission of hospitals is to provide quality care congruent with the needs and expectations of patients, the satisfaction of patients shows that the services are properly performed or not; however, providing services below the expectations, always reduce their credibility and patient confidence (Mendes et al. 2018). In other words, receiving satisfactory care and treatment increases patients' trust in the hospital (Zarei et al. 2015).

It has been shown that the quality of medical services is associated with patient satisfaction (Kim et al. 2017). Satisfaction cannot be only achieved through technology and the personnel's behavior as well as their performance are also effective. Patients' dissatisfaction with 
their negative propaganda provides the grounds for the loss of the hospital (Teshnizi et al. 2018).

Today, the structure of health care and competitive considerations have been modified to the point where patients play a key role in defining quality (Willems \& Ingerfurth 2018). Therefore, patients and their families should be considered as the consumers of healthcare services, and also their needs and expectations be regarded as the main factor for the development of products and healthcare.

Respecting the needs of patients in providing quality assessment makes healthcare responsive to people's needs (Ali, Basu \& Ware 2018). Also, the first step in designing, maintaining, or improving the quality of care is to assess the quality (Mohammadnia et al. 2010), and currently, the quality is determined as the provision of customer-centric services (Jamali 2011). As a result, expectations are one of the most important determinants of the evaluation of patients or their families of the quality of services, and the exact recognition of these expectations is considered as the most important step in defining and delivering high-quality services. One of the current challenges of health care systems is how to respond to patient expectations.

Despite the importance of this issue, recognition of the needs and desires of patients in providing care has been ignored (Girmay et al. 2018). Several studies on the quality of hospital services and patients' satisfaction with hospital care have indicated many challenges and disadvantages in this field. Accordingly, the quality of these services should be continuously monitored by the authorities of hospitals to be aware of the possible problems in different areas timely to resolve them (Willems \& Ingerfurth 2018). Measuring and managing the quality of services are vital for organizations providing health care services (Shabbir \& Malik 2016).

Despite various tools and models in the field of health and treatment, the SERVQUAL model has been used to measure the quality of services in many studies (Abuosi \& Atinga 2013; Belaid et al. 2015). The SERVQUAL model or quality gap was first introduced by Parasuraman et al. in 1985 (Parasuraman, Zeithaml \& Berry 1985). This valid tool is used to evaluate service quality (Ajam et al. 2014).

Collecting sufficient information about the customer perceptions of service quality can help organizations to identify factors that affect their competitive aspect and prevent waste of resources (Shabbir \& Malik 2016). It seems that a reduction in the hospital services quality gap will have a positive effect on patient satisfaction, and consequently organizational performance.

The present study was done to investigate the gap between expectations and perceptions of service quality in five private hospitals according to the patients to provide reference data for creating strategies to improve health care quality.

\section{Materials and Methods}

\section{Design and sample}

This descriptive cross-sectional study was conducted between April and August 2018. The research population was all the patients referring to five private hospitals in Tehran province. The inclusion criterion was patients who had been hospitalized for more than three days. The subjects were recruited by random cluster sampling method. The sample size was estimated as 118 subjects using the Cochran formula. Eight subjects were excluded because of the invalidity of their responses.

\section{Data collection}

The data gathering tools were a demographic questionnaire and the standard SERVQUAL model and service gap questionnaire that was adapted from Parasuraman et al. (1985). It consists of five dimensions in two areas of perceptions and expectations. The five dimensions include tangibles, reliability, responsiveness, assurance, and empathy. Tangibles are facilities, equipment, and appearance of personnel; reliability is the ability to perform the promised services dependably and accurately; responsiveness is employees' willingness to help service recipients and customers; assurance is employee skills, knowledge, and ability to instill a sense of trust and assurance in service recipients, and empathy is understanding the needs of service recipients and individualized attention to each of them (Parasuraman, Zeithaml \& Berry 1985). The questionnaire has 22 items and is scored on a 7-point Likert scale (from $1=$ strongly disagree to $7=$ strongly agree). A higher score on each item shows that the patient's expectations and perceptions about medical services quality is positive.

There are four questions in the tangible dimension, five questions in the reliability dimension, four questions in the responsiveness dimension, four questions in the assurance dimension, and five questions in the empathy dimension. Each participant answered the questionnaire twice. In the first stage, customer's expectations about the quality of services and in the second stage, their per- 
ceptions of the quality were examined. After the calculation of the responses, the gap was determined by the difference between expectations and perceptions. The positive result indicates that the provided services exceed the customer's expectations. If it is negative, it indicates that the provided healthcare services do not meet the expectations of the clients and there is a quality gap.

Score zero means that there is no gap between the quality and the expected healthcare services provided to the clients. The validity and reliability of the Persian version of the questionnaire have been confirmed (Heidarnia et al. 2014). In our study, the validity of the questionnaire was determined using the construct validity method (factor structure) and its reliability was determined by Cronbach's alpha coefficient of 30 primary distributed questionnaires, which was 0.85 .

\section{Data analysis}

Eight questionnaires were excluded from the analysis process due to the invalidity of the responses and finally, 110 questionnaires were analyzed. Initially, the frequency distribution of data was analyzed by the K-S test. Then, the t-test and paired t-test were used. Data were analyzed by SPSS V. 25 software. $\mathrm{P} \leq 0.05$ was regarded as significant in this study.

\section{Results}

The results showed that $70 \%$ of the respondents were female and $30 \%$ were male. The age group of 50 years and older was more than other age groups (39\%) and those in the age group of 31 to 40 years old, had the lowest number $(5.5 \%)$.

According to the above Figure 1, among the quality of health care components, the highest mean was related to the response variable $(\mathrm{M}=3.89)$ and the lowest mean allocated to the tangible variable $(\mathrm{M}=3.11)$.

To analyze the data in two different situations, the tcorrelated (pairwise) test was used. The results of the test are shown in Table 1. The results of Table 1 show that the lowest quality gap (perceived service and expected service) was in the responsiveness dimension (2.96 and 3.28). It reflects more attention from hospital staff and managers to this area, which is the most important strength of hospitals. The amount of service quality gap in other dimensions was as follows: assurance (2.39 and 4.75), empathy (1.36 and 3.19), reliability (2.66 and 3.90), and tangible (2.53 and 3.91).

According to the results of the correlation test for reliability (0.014), assurance ability (0.026), response difference (0.034), empathy difference (0.019), and tangible dimension (0.044), a significant difference was found in the perceived and expected services in all dimensions. It means that there is a significant difference between the patients' perceived service and their expected service quality (Table 2).

\section{Discussion}

Patients are needed to be ensured of receiving highquality services. In the present study, we explored the expectations and perceptions of patients referring to five private hospitals in Tehran about the quality of hospital services to distinguish the gap in hospital service quality. The quality of services reported by patients shows how well the experience with health care has met their expectations, which can affect patient satisfaction and loyalty (Lis, Rodeghier \& Gupta 2011).

According to the results, it was found that there was a significant difference between the five components of

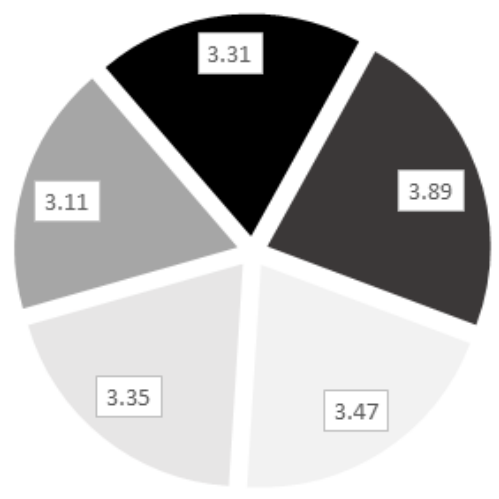

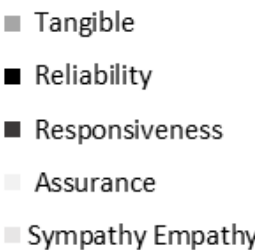

Figure 1. Statistical description of the main varibles of the research 
Table 1. The correlation between patients' perceptions and expectations

\begin{tabular}{lllcl}
\hline \multicolumn{2}{c}{ Quality Dimension } & Mean \pm SD & Average Standard Error & $\mathbf{P}^{*}$ \\
\hline \multirow{2}{*}{ Tangible } & Perceived service & $2.53 \pm 0.083$ & 0.013 & 0.341 \\
& Expected Services & $3.91 \pm 1.03$ & 0.163 & 0.396 \\
Assurance & Perceived service & $2.39 \pm 0.097$ & 0.016 & 0.412 \\
& Expected Services & $4.75 \pm 1.22$ & 0.141 & 0.016 \\
Responsiveness & Perceived service & $2.96 \pm 0.097$ & 0.141 & 0.352 \\
& Expected Services & $3.28 \pm 1.22$ & 0.038 & 0.133 \\
Empathy & Perceived service & $1.36 \pm 0.102$ & 0.108 & 0.374 \\
\hline & Expected Services & $3.19 \pm 1.06$ & 0.124 & \\
\hline
\end{tabular}

*: T-test.

made to improve employee behavior and communication with patients. Other studies also reported the lowest score for empathy (Zarei et al. 2012).

The highest expectation and quality gap were related to the assurance dimension. The high score of patients' expectations in the assurance dimension shows that doing things right in the hospital, a sufficient number of the staff and their up-to-date knowledge, and how the employees deal with them are very important for the patients. The high gap in this dimension suggests that based on the patient's opinion, physicians and hospital staff did not have sufficient knowledge to help patients and did not deal with them with respect. They failed to create a sense of security and confidence in patients (Zarei et al. 2012). It seems that hospital staff do not fulfill their obligations in the best possible way or do not have enough knowledge and skills. relationship between physicians, nurses, and other staff with patients (Zarei et al. 2012). Thus, efforts should be

Table 2. The intra-group effect among the dimensions of services quality

\begin{tabular}{|c|c|c|c|c|c|c|c|}
\hline $\begin{array}{l}\text { The difference between per- } \\
\text { ceived and expected services }\end{array}$ & Mean \pm SD & $\begin{array}{l}\text { Mean Stan- } \\
\text { dard Error }\end{array}$ & Lower Limit & Upper Limit & t-Statistics & $\begin{array}{l}\text { Degrees of } \\
\text { Freedom }\end{array}$ & $\mathbf{P}^{*}$ \\
\hline Reliability & $0.1081 \pm 1.072$ & 0.1211 & -0.1334 & 0.3496 & 0.692 & 109 & 0.014 \\
\hline Assurance & $0.1183 \pm 1.086$ & 0.1026 & -0.1258 & 0.3620 & 0.603 & 109 & 0.026 \\
\hline Responsiveness & $0.1230 \pm 1.094$ & 0.1058 & -0.1139 & 0.3861 & 0.678 & 109 & 0.034 \\
\hline Empathy & $0.1532 \pm 1.044$ & 0.0893 & -0.879 & 0.4056 & 0.741 & 109 & 0.019 \\
\hline Tangible & $0.1392 \pm 1.034$ & 0.0831 & -1.031 & 0.488 & 0.592 & 109 & 0.044 \\
\hline
\end{tabular}

*: T-test.

Client- Centered Nursing Care 
Comparing the results of this study with some other studies (Teshnizi et al. 2018; Torabipour et al. 2016), it can be concluded that there is a gap in the quality of services provided in most hospitals. However, there would be differences in the number of medical staff, the use of modern equipment and technology, physical space, and educational facilities.

It seems that holding briefings for staff on how to communicate with the patient and keeping the dignity of the patient and conducting workshops and new diagnostic and therapeutic courses to provide services with the expected quality of patients will be effective in reducing the quality gap. The need to improve the quality of health services in hospitals is the most important competitive advantage in hospitals that distinguishes them from each other.

Generally, hospitals need to educate their staff about patients' needs and expectations and how to effectively meet those needs and expectations (Choi et al. 2005) To reduce the gap between patients' perceptions and expectations, it is recommended that studies like the current study be repeated every year and its results be presented to the managers, medical staff, and hospital managers.

\section{Conclusions}

Based on the results, there was a significant difference between the patient's perceived and expected services, which is indicative of the poor quality of provided services and patients' dissatisfaction. According to the findings, the assurance dimension had the greatest gap. To reduce or eliminate the existing gap, it is suggested that hospitals consider strategic and operational planning to refine hospitalization and improve patients' experiences.

\section{Ethical Considerations}

\section{Compliance with ethical guidelines}

All ethical principles are considered in this article. The participants were informed about the purpose of the research and its implementation stages; they were also assured about the confidentiality of their information; moreover, they were free to leave the study whenever they wished, and if desired, the research results would be available to them.

\section{Funding}

This research did not receive any grant from funding agencies in the public, commercial, or non-profit sectors.

\section{Authors' contributions}

All authors contributed in preparing this article.

\section{Conflict of interest}

The authors declared no conflict of interest.

\section{Acknowledgments}

The authors would like to thank the managers of the hospitals and their staff for their cooperation in conducting the study.

\section{References}

Abuosi, A. A., \& Atinga R. A., 2013. Service quality in healthcare institutions: Establishing the gaps for policy action. International Journal of Health Care Quality Assurance, 26(5), pp. 481-92. [DOI:10.1108/IJHCQA-12-2011-0077] [PMID]

Ajam, M., et al., 2014. [Assessing quality of healthcare service by the servqual model: A case study of a field hospital (Persian)]. Journal of Military Medicine, 15(4), pp. 273-9. http:// militarymedj.ir/article-1-1088-en.html

Akdere, M., Top M., \& Tekingündüz S., 2020. Examining patient perceptions of service quality in Turkish hospitals: The SERVPERF model. Total Quality Management \& Business Excellence, 31(3-4), pp. 342-52. [DOI:10.1080/14783363.2018 .1427501]

Ali, S. S., Basu A., \& Ware N., 2018. Quality measurement of Indian commercial hospitals-using a SERVQUAL framework. Benchmarking: An International Journal, 25(3), pp. 815-37. [DOI:10.1108/BIJ-05-2016-0060]

Asefzadeh, S., et al., 2016. Evaluation of the quality of health service providers: The Iranian people perspective 2014. Electronic Physician, 8(3), pp. 2073-89. [DOI:10.19082/2073] [PMID] [PMCID]

Belaid, H., et al., 2015. The quality of health services in bechar public hospital institution. International Journal of Social Sciences, 4(2), pp. 93-109. https://ideas.repec.org/p/sek/ iacpro/0101005.html

Choi, K. S., et al., 2005. The service quality dimensions and patient satisfaction relationships in South Korea: comparisons across gender, age and types of service. Journal of Services Marketing, 19(3), pp. 140-9. https://www.emerald.com/ insight/content/doi/10.1108/08876040510596812/full/html

Girmay, A., et al., 2018. Patients expectation strongly associated with patients perception to nursing care: Hospital based cross sectional study. BMC Research Notes, 11(1), p. 310. [DOI:10.1186/s13104-018-3447-x] [PMID] [PMCID]

Heidarnia, M. A., et al., 2014. [Cross cultural adaptation and assessing validity and reliability of SERVQUAL questionnaire in hospital service quality (Persian)]. Research in 
Medicine, 38(2), pp. 98-105. http://pejouhesh.sbmu.ac.ir/ article-1-1339-en.html

Jamali, R., 2011. Providing a model for improving the quality of education in higher education institutions SERVQUAL and QFD approach to fuzzy graduate students in Yazd University, [Master's Thesis] (Persian)].

Kim, C. E., et al., 2017. Quality of medical service, patient satisfaction and loyalty with a focus on interpersonal-based medical service encounters and treatment effectiveness: A cross-sectional multicenter study of Complementary And Alternative Medicine (CAM) hospitals. BMC Complementary and Alternative Medicine, 17(1), p. 174. [DOI:10.1186/ s12906-017-1691-6] [PMID] [PMCID]

Lis, C. G., Rodeghier M., \& Gupta D., 2011. The relationship between perceived service quality and patient willingness to recommend at a national oncology hospital network. BMC Health Services Research, 11(1), p. 46. [DOI:10.1186/14726963-11-46] [PMID] [PMCID]

Mendes, I. A. C., et al., 2018. Expectations and perceptions of clients concerning the quality of care provided at a Brazilian hospital facility. Applied Nursing Research, 39, pp. 211-6. [DOI:10.1016/j.apnr.2017.11.024] [PMID]

Mohammadnia, M., et al., 2010. [Survey on nursing service quality by SERVQUAL at Tehran social security organization hospitals (Persian)]. Journal of Hospital, 8(3-4), pp. 6873. http://jhosp.tums.ac.ir/article-1-100-en.html

Mousavi, M., et al., 2019. The satisfaction of ischemic heart disease patients with nursing care in emergency department. Journal of Client-Centered Nursing Care, 5(3), pp. 203-10. [DOI:10.32598/JCCNC.5.3.203]

Nadi, A., et al., 2016. Patients' expectations and perceptions of service quality in the selected hospitals. Medical Archives, 70(2), pp. 135-9. [DOI:10.5455/medarh.2016.70.135-139] [PMID] [PMCID]

Parasuraman, A., Zeithaml, V. A. \& Berry, L. L., 1985. A conceptual model of service quality and its implications for future research. Journal of Marketing, 49(4), pp. 41-50. [DOI:10 $.1177 / 002224298504900403]$

Rezaei, S., et al., 2016. Measurement of quality of educational hospital services by the SERVQUAL model: The Iranian patients' perspective. Electronic Physician, 8(3), pp. 2101-6. [DOI:10.19082/2101] [PMID] [PMCID]

Shabbir, A. \& Malik, S. A., 2016. Measuring patients' healthcare service quality perceptions, satisfaction, and loyalty in public and private sector hospitals in Pakistan. International Journal of Quality \& Reliability Management, 33(5), pp. 53857. [DOI:10.1108/IJQRM-06-2014-0074]

Sokhanvar, M. \& Mosadeghrad, A., 2017. [Organizational culture of selected hospitals of Tehran City (Persian)]. Journal of Hospital, 16(2), pp. 46-57. http:/ /jhosp.tums.ac.ir/article1-5671-en.html

Tabibi, S. J., et al., 2012. [Assessment of health care services in outpatient clinics based on SERVQUAL model in hospitals of Tehran (Persian)]. Journal of Payavard Salamat, 5(4), pp. 49-56. http:/ / payavard.tums.ac.ir/article-1-62-en.html

Teshnizi, S. H., et al., 2018. Assessing quality of health services with the SERVQUAL model in Iran: A systematic review and meta-analysis. International Journal for Quality in Health Care, 30(2), pp. 82-9. [DOI:10.1093/intqhe/mzx200] [PMID]

Torabipour, A., et al., 2016. Analyzing the quality Gapsin the services of rehabilitation centers using the SERVQUAL technique in Ahvaz, Iran. Jundishapur Journal of Health Sciences, 8(1), p. e60320. [DOI:10.17795/jijhs-32560]

Uno, M., 2018. The concepts of "patient suffering" and "favorable interaction" in nurse-patient conflicts based on gaps in perception. Biomedical Journal of Scientific \& Technical Research, 2(1), pp. 2235-42. [DOI:10.26717/ BJSTR.2018.02.000666]

Willems, J., \& Ingerfurth, S., 2018. The quality perception gap between employees and patients in hospitals. Health Care Management Review, 43(2), pp. 157-67. [DOI:10.1097/ HMR.0000000000000137] [PMID]

Wong, A., \& Sohal, A., 2003. Service quality and customer loyalty perspectives on two levels of retail relationships. Journal of Services Marketing, 17(5), pp. 495-513. [DOI:10.1108/08876040310486285]

Zarei, E., et al., 2015. The effect of hospital service quality on patient's trust. Iranian Red Crescent Medical Journal, 17(1), p. e17505. [DOI:10.5812/ircmj.17505] [PMID] [PMCID]

Zarei, E., et al., 2012. [Hospital services quality from patients' point of view: A cross-sectional study in Tehran private hospitals (Persian)]. Journal of Payavard Salamat, 5(4), pp. 6676. http:// payavard.tums.ac.ir/article-1-64-en.html 
This Page Intentionally Left Blank 